\title{
¿Feedback Processes Modulating the Sensitivity of Atlantic Thermohaline Circulation to Freshwater Forcing Timescales
}

\author{
Hyo-Jeong Kim, ${ }^{a}$ SoOn-IL AN, ${ }^{\text {a, }}$ SoOng-Ki Kim, ${ }^{a}$ AND JAE-Heung PARK ${ }^{\mathrm{b}}$ \\ ${ }^{a}$ Department of Atmospheric Sciences/Irreversible Climate Change Research Center, Yonsei University, Seoul, South Korea \\ ${ }^{\mathrm{b}}$ Division of Environmental Science and Engineering, Pohang University of Science and Technology, Pohang, South Korea
}

(Manuscript received 23 November 2020, in final form 18 March 2021)

\begin{abstract}
Paleoproxy records indicate that abrupt changes in thermohaline circulation (THC) were induced by rapid meltwater discharge from retreating ice sheets. Such abrupt changes in the THC have been understood as a hysteresis behavior of a nonlinear system. Previous studies, however, primarily focused on a near-static hysteresis under fixed or slowly varying freshwater forcing (FWF), reflecting the equilibrated response of the THC. This study aims to improve the current understanding of transient THC responses under rapidly varying forcing and their dependency on forcing time scales. The results simulated by an Earth system model suggest that the bifurcation is delayed as the forcing time scale is shorter, causing the Atlantic meridional overturning circulation collapse and recovery to occur at higher and lower FWF values, respectively. The delayed shutdown/recovery occurs because bifurcation is determined not by the FWF value at the time but by the total amount of freshwater remaining over the THC convection region. The remaining freshwater amount is primarily determined by the forcing accumulation (i.e., timeintegrated FWF), which is modulated by the freshwater/salt advection by ocean circulations and freshwater flux by the atmospheric hydrological cycle. In general, the latter is overwhelmed by the former. When the forced freshwater amount is the same, the modulation effect is stronger under slowly varying forcing because more time is provided for the feedback processes.
\end{abstract}

KEYWORDS: Meridional overturning circulation; Thermohaline circulation; Atmosphere-ocean interaction; Climate variability; Oceanic variability

\section{Introduction}

Proxy records indicate that severe climate changes in the past were induced by changes in the intensity of the Atlantic thermohaline circulation [THC; interchangeable with the Atlantic meridional overturning circulation (AMOC), especially when the overturning is primarily density driven], which was triggered by meltwater release from retreating ice sheets (Flower et al. 2011; Clark et al. 2001; Vetter et al. 2017; Clark et al. 2002). As an example, the emergence of North Atlantic Ocean warming hole in current and future climates (Kim and An 2013; Keil et al. 2020) can be analogous to a sudden temperature drop associated with AMOC shutdown during the last deglaciation (e.g., the onset of Younger Dryas). Accordingly, the impact of the North Atlantic freshwater forcing (FWF) on the AMOC has attracted considerable attention from the climate research community (e.g., Rahmstorf 1996; Clark et al. 2001; Bitz et al. 2007; Böning et al. 2016; Jackson and Wood 2018; Alkhayuon et al. 2019; Kim and An 2019; Hawkins et al. 2011; Wood et al. 2019).

A notable feature of the paleo-AMOC is that its intensity changed abruptly, indicating phase transitions between on and off states (Broecker et al. 1985; Rahmstorf 2002; McManus et al. 2004; Delworth et al. 2008; Henry et al. 2016). This nonlinearity has been explored using a hierarchy of climate models and has been understood as a hysteresis behavior with saddle-node bifurcations under increasing/decreasing FWF (Rahmstorf et al.

¿ Denotes content that is immediately available upon publication as open access.

Corresponding author: Soon-Il An, sian@yonsei.ac.kr
2005; Hawkins et al. 2011; Wood et al. 2019; An et al. 2021). In previous studies, it was often assumed that the AMOC response to FWF was close to equilibrium, because the FWF varied sufficiently slowly with time (Rahmstorf 1995; Hofmann and Rahmstorf 2009; Hu et al. 2012). However, proxy records indicate that meltwater flux in the real world may vary rapidly with time, rather than being quasi-steady with respect to the AMOC adjustment time scale (Fairbanks 1989; Aharon 2003; Wickert et al. 2013; Vetter et al. 2017). Under such time-varying forcing, a system's response may significantly differ from that under an equilibrium, depending on how fast the system can adjust to the varying forcing. In this case, not only the adjustment time scale of the system but also the forcing time scale can be important.

Dependencies of bifurcations on the forcing time scale have been reported in other scientific fields such as acoustics, laser physics, engineering, and neuroscience (Mandel and Erneux 1987; Mannella et al. 1987; Baer and Gaekel 2008; Bergeot et al. 2014; Premraj et al. 2016; Bonciolini et al. 2018). It has been shown that time-varying forcing can postpone bifurcation of a dynamical system so that the bifurcation requires a larger parameter change beyond the static bifurcation point-that is, the parameter value at which the bifurcation would occur if the quasi-static equilibrium is satisfied (e.g., An et al. 2021). This bifurcation delay of the system is caused by its failure to adapt to the changing environment, due to inertia that keeps the system close to its initial state (Hughes et al. 2013).

In a climate system, the ocean provides such inertia. However, only a few studies to date have considered different forcing time scales in simulating the AMOC hysteresis (Alkhayuon et al. 2019; Stocker and Schmittner 1997). Stocker and Schmittner (1997, hereinafter SS1997) examined the 


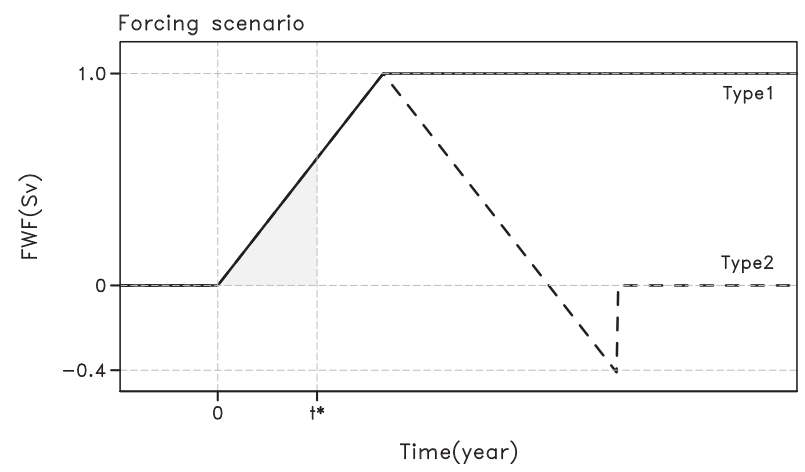

FIG. 1. Schematic representation of forcing scenarios used in this study. In type 1, the forcing linearly increases until it reaches the predefined maximum value ( $1 \mathrm{~Sv}$ ) and then remains fixed. In type 2 , the forcing starts to decrease at the same rate as it was increased as soon as it hits the maximum value. The time at which the area under the curve becomes $10 \mathrm{~m}$ in the equivalent sea level elevation (eSLE) is denoted by $t^{*}$. Note that $t^{*}$ and the corresponding $y$-axis (FWF) value vary depending on the forcing rate.

AMOC response under $\mathrm{CO}_{2}$ forcing, which increased to a fixed level at different rates. They used a zonally averaged three-basin ocean model coupled with an energy-balance atmospheric model and found that if the $\mathrm{CO}_{2}$ is increased sufficiently slowly, the AMOC weakens at first but eventually recovers its initial strength. If the $\mathrm{CO}_{2}$ is increased rapidly, the AMOC enters a collapsed state even if the final $\mathrm{CO}_{2}$ value is the same as the slowly increased case. Alkhayuon et al. (2019, hereinafter A2019) found qualitatively similar results using a simple threebox model with freshwater flux forcing. Recently, An et al. (2021) also performed sensitivity experiments of the AMOC to the FWF time scale using H. Stommel's two-box model and an Earth system model. Their main focus was dynamic hysteresis of the AMOC under sinusoidal FWF, whose area inside the hysteresis loop increases with the forcing frequency, indicating delayed bifurcation under rapid forcing. This study, being an extension of An et al. (2021), also explores the rate-dependent hysteresis behavior of the AMOC, but we further address the physical mechanism of how forcing rates determine the timing of the AMOC collapse. We specifically explore the relationship between accumulated forcing and bifurcation points as well as feedback processes that modulate the relationship. To this end, we conducted a sensitivity test similar to An et al. (2021) using an Earth system model.

The remainder of this paper is organized as follows: section 2 introduces the model configurations and experimental design. Section 3 describes the simulated results and elucidates the physical processes that contribute to different timings of the AMOC collapse under various forcing rates. In section 4, a comparison with previous studies is given, and section 5 summarizes the findings.

\section{Methods}

\section{a. Model and experiments}

We used ECBilt-CLIO-VECODE-LOCH-AGISM (LOVECLIM), version 1.3, a three-dimensional Earth system model (Goosse et al. 2010). LOVECLIM captures well the overall large-scale features in the climate with an efficient computing speed, which makes it suitable for long-term simulations that are required in this study. The atmospheric model (ECBilt), which is relatively simplified, is a spectral model that solves the quasigeostrophic potential vorticity equation (Opsteegh et al. 1998). Its horizontal resolution corresponds to $5.6^{\circ}$, and it has three vertical levels. The ocean model, CLIO, solves primitive equations at a horizontal resolution of $3^{\circ}$ and vertical resolution of 20 levels (Goosse and Fichefet 1999). Freshwater volume pile-up is not explicitly simulated in the model. Instead, the freshwater forcing is treated as a negative salinity flux at the surface, so this study only analyzes the influence of surface freshening on the AMOC. The atmospheric and oceanic models are coupled to a dynamic vegetation model (VECODE; Brovkin et al. 1997) with the ice sheet (AGISM) and carbon cycle (LOCH) models deactivated.

To test the sensitivity of AMOC hysteresis on the forcing time scale, we devised FWF scenarios, as shown in Fig. 1, and applied forcing for the North Atlantic surface $\left(50^{\circ}-70^{\circ} \mathrm{N}, 15^{\circ}-\right.$ $\left.70^{\circ} \mathrm{W}\right)$. In type- 1 scenarios, the FWF linearly increases from 0 to $1 \mathrm{~Sv}\left(1 \mathrm{~Sv} \equiv 10^{6} \mathrm{~m}^{3} \mathrm{~s}^{-1}\right)$ at different rates and then remains fixed. We performed 11 experiments for type 1, with rates of $0.1,0.05,0.02,0.01,0.005,0.002,0.001,0.0005,0.0002,0.0001$, and $0.00005 \mathrm{~Sv} \mathrm{yr}^{-1}$, corresponding to $10,20,50,100,200,500$, $1000,2000,5000,10000$, and 20000 years to $1-\mathrm{Sv}$ forcing. In type 2, the FWF initially increases up to $1 \mathrm{~Sv}$, similar to type 1 , but decreases back at the same rate until it reaches $-0.4 \mathrm{~Sv}$ (e.g., Hawkins et al. 2011). Seven rates of forcing were applied for the type-2 scenario; $0.00125,0.001,0.00083,0.00066$, $0.00056,0.0005$, and $0.00042 \mathrm{~Sv} \mathrm{yr}^{-1}$, corresponding to 800 , $1000,1200,1500,1800,2000$, and 2400 years to reach $1-\mathrm{Sv}$ forcing. While type-1 experiments cover a wider range of forcing time scales, type-2 experiments cover a complete hysteresis loop. For the physical mechanism of bifurcation delay, we focus on the collapsing branch of the AMOC by using type 1. Freshwater compensation outside the forcing region was not applied so that the global mean salinity decreased as the forcing increased.

\section{b. Freshwater budget}

Under equilibrium, the surface freshwater flux by evaporation $E$, precipitation $P$, runoff $R$, and ice melt $M$ in the Atlantic basin is in balance with transport by the THC and azonal circulations and diffusive processes (de Vries and Weber 2005):

$$
E-P-R-M=\tilde{W}_{\mathrm{THC}}+\tilde{W}_{\mathrm{az}}+\tilde{W}_{\mathrm{diff}} .
$$

In Eq. (1), $\tilde{W}$ represents "net" freshwater influx into the basin, incorporating the effect from both the southern and northern boundaries. This is slightly different from the version used by de Vries and Weber (2005) in which transports at the southern and northern boundaries were considered separately. At the basin scale, the effects of runoff and ice production are so small that they are ignored in further analysis.

In this study, we consider an unequilibrated state of the system by adding a tendency term for freshwater in the basin $\left(V_{\mathrm{FW}}\right)$ and forcing $(\mathrm{FWF})$, which gives 


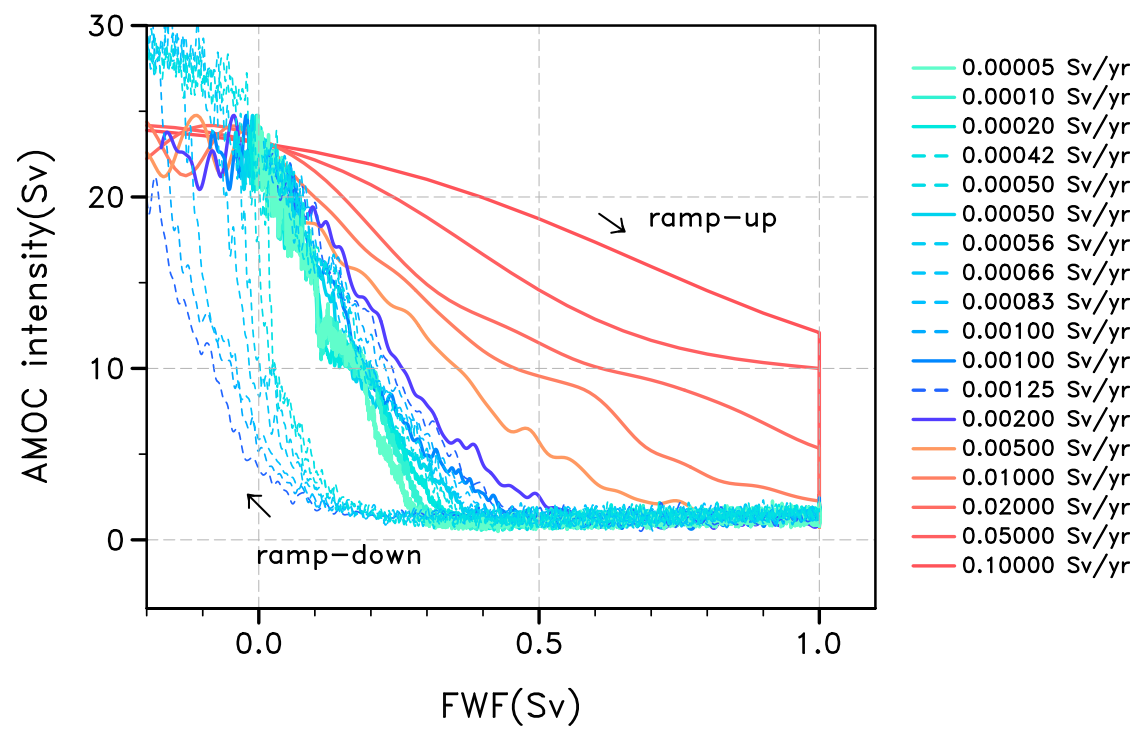

FIG. 2. Collapsing (ramp up) branch of the AMOC hysteresis for type 1 (solid) and full loops for type 2 (dashed). The AMOC index is defined as the maximum streamfunction in the North Atlantic Ocean north of $20^{\circ} \mathrm{N}$ and below $500 \mathrm{~m}$. A 15-yr Lanczos low-pass filter was applied here for visual clarity. Bluish colors represent the static-dominant regime and reddish colors represent the dynamic-dominant regime, which is described in the text.

$$
\frac{d V_{\mathrm{FW}}}{d t}=P-E+\mathrm{FWF}+\tilde{W}_{\mathrm{THC}}+\tilde{W}_{\mathrm{az}}+\tilde{W}_{\mathrm{diff}} .
$$

In Eq. (2), $V_{\mathrm{FW}}$ can be defined as

$$
V_{\mathrm{FW}}=V \ln \left(\hat{S}_{0} / \hat{S}_{1}\right),
$$

where $\hat{S}$ represents the basin-averaged salinity, $V$ is the total volume of the basin, and the subscripts 0 and 1 are used for the initial and final states (see the appendix). To obtain $\tilde{W}_{\mathrm{THC}}$ and $\tilde{W}_{\mathrm{az}}$, first, the meridional freshwater transport across a certain latitude $\phi$ is written as

$$
\begin{gathered}
w_{\mathrm{THC}}(\phi)=-\frac{1}{S^{*}} \int\langle v(\phi, z)\rangle\left[\overline{S(\phi, z)}-S^{*}\right] d z \text { and } \\
w_{\mathrm{az}}(\phi)=-\frac{1}{S^{*}} \int\langle\dot{v}(\lambda, \phi, z) \dot{S}(\lambda, \phi, z)\rangle d z,
\end{gathered}
$$

respectively (Rahmstorf 1996; de Vries and Weber 2005; Bitz et al. 2007; Liu and Liu 2013; Liu et al. 2017). In the equations, $v$ and $S$ are the meridional current and salinity, and $S^{*}$ is the reference salinity taken from the global mean of $34.7 \mathrm{psu}$. The overbar and the angle brackets indicate a zonal mean and a zonal integral, respectively. The dot denotes a deviation from the zonal mean at a certain longitude $\lambda$. Then, $\tilde{W}_{\mathrm{THC}}$ and $\tilde{W}_{\mathrm{az}}$, the net imports into the basin, are defined as $\tilde{W}_{\mathrm{THC}}=w_{\mathrm{THC}}\left(33^{\circ} \mathrm{S}\right)-w_{\mathrm{THC}}\left(70^{\circ} \mathrm{N}\right)$ and $\tilde{W}_{\mathrm{az}}=w_{\mathrm{az}}\left(33^{\circ} \mathrm{S}\right)-w_{\mathrm{az}}\left(70^{\circ} \mathrm{N}\right)$, respectively (Liu and Liu 2013). Note that $\tilde{W}_{\text {THC }}$ is used here to quantify freshwater convergence rather than to indicate stability (which will be further discussed in section 3).

By integrating Eq. (2) over time, it also holds that

$$
V_{\mathrm{FW}}=\int\left(P-E+\mathrm{FWF}+\tilde{W}_{\mathrm{THC}}+\tilde{W}_{\mathrm{az}}+\tilde{W}_{\mathrm{diff}}\right) d t .
$$

Using these equations, we quantified contributions from each process to freshening (salifying) the Atlantic basin.

\section{Results}

\section{a. Bifurcation delay}

Figure 2 shows the ramp-up branches of hysteresis for type 1 and full hysteresis loops for type 2. It is noticeable that during the ramp-up period, the AMOC under fast-varying forcing collapses at a higher FWF value, indicating that a larger parameter change is required. Similarly, during the ramp-down period, the AMOC under fast-varying forcing recovers at a lower value of FWF. In other words, bifurcation is delayed so that the area inside the hysteresis loop expands as the forcing varies faster. Note that the term "delay" is in terms of the bifurcation parameter (in this case, the FWF), not the time.

In Fig. 3, simulated bifurcation points (black dots and crosses) for the AMOC collapse are shown with relative contributions from the static and dynamic bifurcation. Here, the static bifurcation point is fixed regardless of the forcing rate, and it can be obtained by repeating a number of simulations for constant FWF values. To save computational cost, the static bifurcation point for AMOC collapse was estimated to be $0.264 \mathrm{~Sv}$ by an exponential fitting of dynamic bifurcations. Meanwhile, the simulated bifurcation point is measured as a point at which the 101-yr running-averaged AMOC intensity becomes lower than a predefined value. The AMOC index has a nonzero residual value by its definition even after the shutdown; thus, the criterion is considered to be $1.7 \mathrm{~Sv}$. The results are not qualitatively sensitive to the filter or criterion (not shown here). The difference between the simulated bifurcation point and the static bifurcation point is termed the dynamic bifurcation, which is a measurement of the delay 


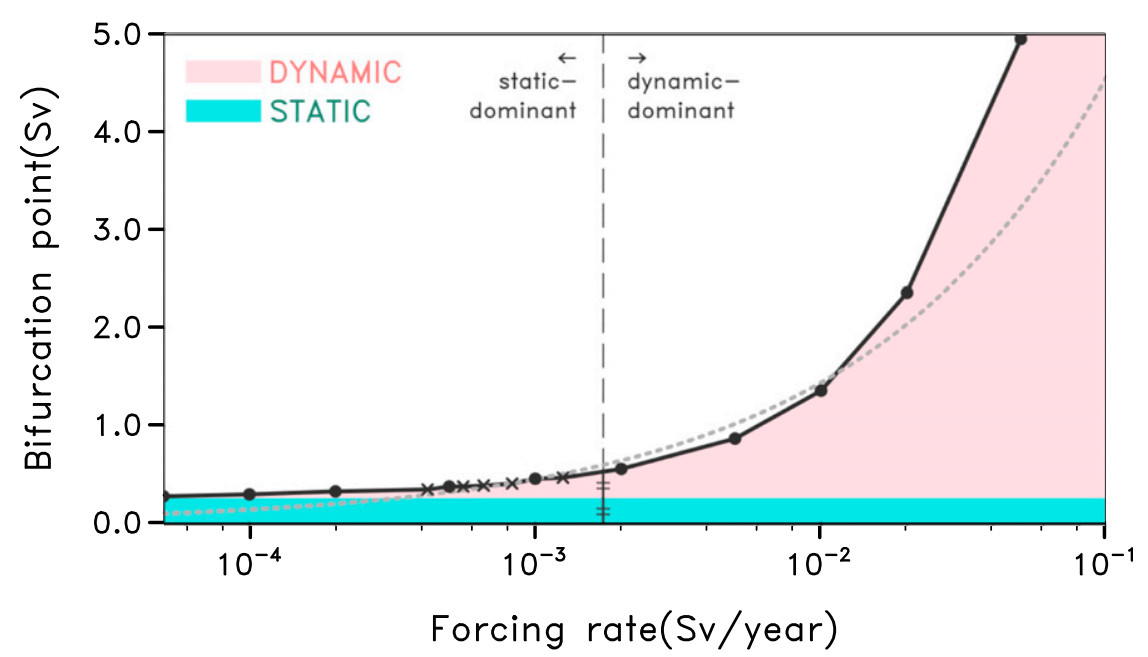

FIG. 3. Relative contributions of static (blue-green shading) and dynamic (pink shading) bifurcation to the final bifurcation point (black line). The static bifurcation point was estimated on the basis of exponential fitting. Dots were obtained from the type- 1 simulations, and cross marks were obtained from type 2. For this figure only, the FWF was adjusted to keep increasing up to $10 \mathrm{~Sv}$ for the fastest four rates $\left(0.01,0.02,0.05\right.$, and $\left.0.1 \mathrm{~Sv} \mathrm{yr}^{-1}\right)$ for which bifurcation is not accomplished until the FWF reaches $1 \mathrm{~Sv}$. The point at which the contribution becomes the same was estimated through the interpolation and marked as a vertical line. Gray short-dashed line represents a curve of TIFWF $=10 \mathrm{~m}$ (see text).

effect caused by the forcing. Figure 3 shows that beyond a certain value (approximately $0.0017 \mathrm{~Sv} \mathrm{yr}^{-1}$ ) of the forcing rate, dynamic bifurcation becomes more dominant in determining the final bifurcation point. Although the threshold may vary depending on the criterion of the AMOC intensity, which is currently set to $1.7 \mathrm{~Sv}$, a sensitivity test revealed that the threshold is insensitive to the criterion (the threshold of approximately $0.002-0.005 \mathrm{~Sv} \mathrm{yr}^{-1}$ for the criterion of $1.7-15 \mathrm{~Sv}$ ). For convenience, we divided the experiments into two regimes using $0.0017 \mathrm{~Sv} \mathrm{yr}^{-1}$ as a threshold: the static-dominant regime in which forcing varies at a rate lower than $0.0017 \mathrm{~Sv} \mathrm{yr}^{-1}$ and the dynamic-dominant regime in which forcing varies at a rate higher than $0.0017 \mathrm{~Sv} \mathrm{yr}^{-1}$ (Fig. 3). It will be shown in the next subsections that the interactions between physical variables differ depending on dynamic or static dominance.

\section{b. Mechanisms}

\section{1) FORCING ACCUMULATION AND SLOW ADJUSTMENT OF THE SYSTEM}

In the experiments described in section 2 , the control variable is freshwater flux $\left(\mathrm{m}^{3} \mathrm{~s}^{-1}\right)$. Thus, time-integrated forcing $\left[\int \mathrm{FWF}(t) d t\left(\mathrm{~m}^{3}\right)\right]$ represents the total volume of the freshwater given in the forcing area. Until the same transient value of the FWF is obtained, the time-integrated FWF (TIFWF) is much smaller for fast-varying forcing. This enables the North Atlantic surface density to remain relatively high (Fig. 4). The sinking motion of the AMOC can be significantly affected by the stratification in the North Atlantic (Kim and An 2019; Heuze et al. 2020), which largely relies on surface density (this point will be further discussed in Fig. 6). Therefore, the lower freshwater accumulation and the resulting higher surface density in the fast-varying forcing maintain a strong AMOC intensity (Fig. 5). This forcing accumulation effect, along with the slow adjustment to forcing, delays a bifurcation. Here, a question might be raised as to why constant forcing below the static bifurcation point does not induce tipping while the integration infinitely increases. This is because a system subjected to constant forcing eventually adjusts to it, whereas a slow system subjected to time-varying forcing does not. When the system reaches a new equilibrated state through adjustment, constant forcing may no longer be regarded as a perturbation. In this case, considering the forcing accumulation effect is inappropriate.

Interestingly, in Fig. 5, the surface density-AMOC relationship is almost independent of the forcing rate in the staticdominant regime (bluish lines) during the ramp-up period. This implies that the AMOC response to the surface density closely follows that of the quasi-equilibrium. As the FWF lowers the surface density, the vertical density profile in the sinking region is stratified and becomes more stable (Fig. 6). Under the slow-to-moderate forcing, there is enough time for the circulation to adapt to the vertical stratification change. Thus, static bifurcation, regulated by equilibrated processes, primarily determines the bifurcation timing in this regime. Conversely, the relationship changes with the rate once it exceeds $0.002 \mathrm{~Sv} \mathrm{yr}^{-1}$. In this regime, the forcing varies so quickly that the AMOC fails to adjust to the surface buoyancy changes. Therefore, the AMOC change and its collapse point become highly sensitive to the forcing rate (Figs. 3 and 5), causing the dynamic bifurcation to become dominant. Figure 5 also indicates that the AMOC-surface density relationship differs 


\section{Surface density@FWF=0.2Sv}
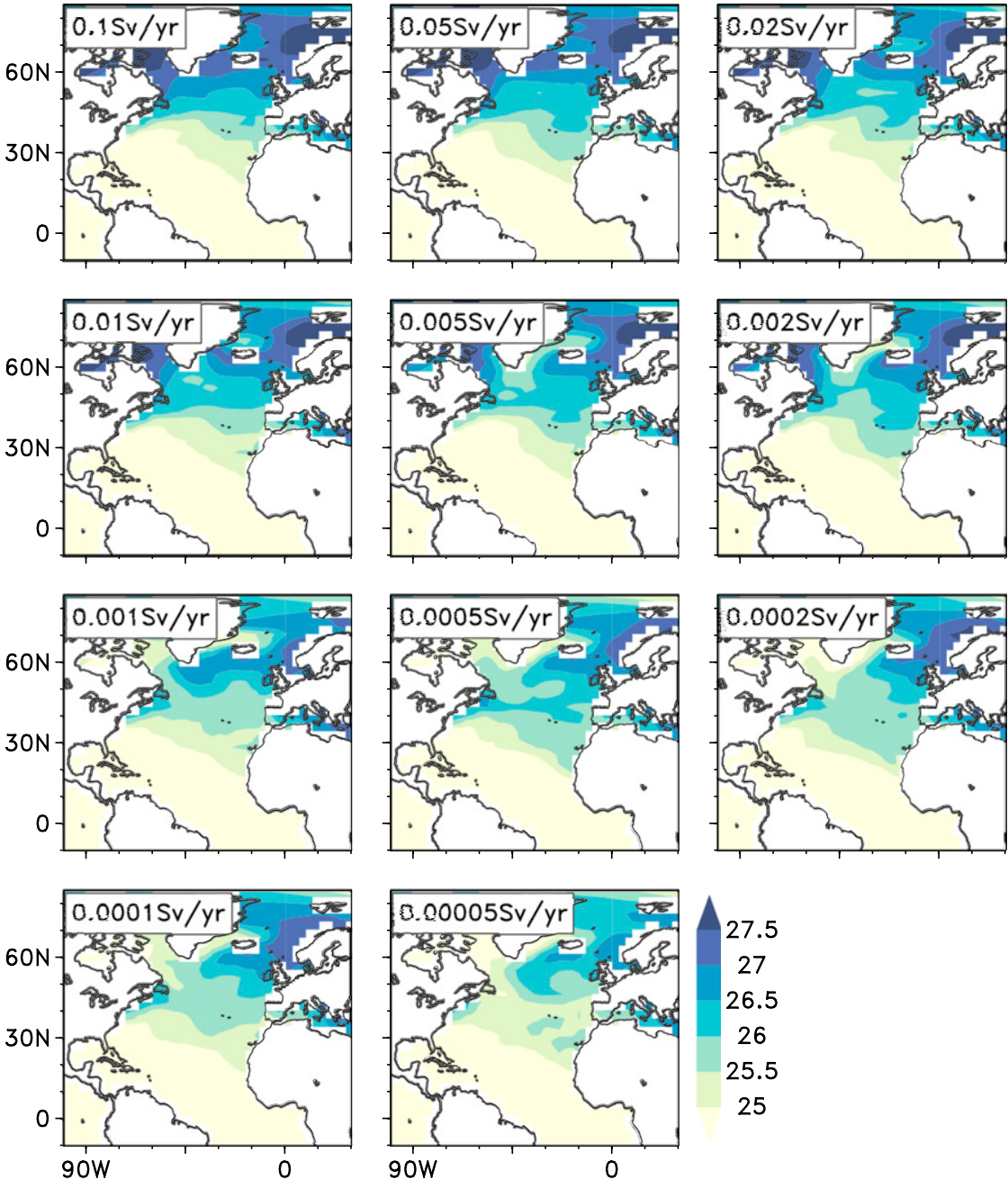

27.5

27

26.5

26

25.5

25

FIG. 4. Annual-mean Atlantic surface density distributions $\left(\mathrm{kg} \mathrm{m}^{-3}-1000\right)$ for type- $1 \mathrm{ex}-$ periments when the FWF is $0.2 \mathrm{~Sv}$.

between ramp-up and ramp-down periods even for the same forcing rate (dashed lines) and that there arises a rate dependency in the static-dominant regime during the ramp-down. Since the cumulative effect from the ramp-up period can affect the results in the ramp-down period, we focused on the physical processes that are relevant to the AMOC collapse in this study.

To get further insight into the relationship between TIFWF and bifurcation point, a constant-TIFWF line (gray shortdashed) is overlaid on the simulated bifurcation points in Fig. 3, where a line for $10 \mathrm{~m}$ of TIFWF [in equivalent in sea level elevation (eSLE)] is shown. That is, if forcing varies at $10^{-4} \mathrm{~Sv} \mathrm{yr}^{-1}, 10 \mathrm{~m}$ of TIFWF is achieved when FWF is approximately $0.15 \mathrm{~Sv}$. If forcing varies at $10^{-1} \mathrm{~Sv} \mathrm{yr}^{-1}$, TIFWF becomes $10 \mathrm{~m}$ when FWF is about $4.8 \mathrm{~Sv}$, and so on. The simulated bifurcation points (black solid) seem to follow this constant-TIFWF line, especially under moderate forcing rates, indicating that bifurcation tends to occur when TIFWF is about
$10 \mathrm{~m}$. Therefore, Fig. 3 implies that the bifurcation point is primarily determined by the total amount of freshwater input (i.e., TIFWF).

Similarly, Jackson and Wood (2018) and A2019 discussed the usefulness of time-integrated forcing as an indicator of the bifurcation point, using a state-of-the-art eddy-permitting model and a conceptual three-box model, respectively. They showed a similar result for the bifurcation point and TIFWF (e.g., Fig. 11 in A2019), but they concluded that the integrated forcing was not a useful indicator for a bifurcation point because the relationship is not exact (bifurcation points are not located "exactly" on a constant TIFWF line). However, the above analysis suggests that TIFWF plays an important role in determining bifurcation points, and the exact relationship could be modulated by other physical processes. In the remainder of this section, possible modulation processes are proposed. 


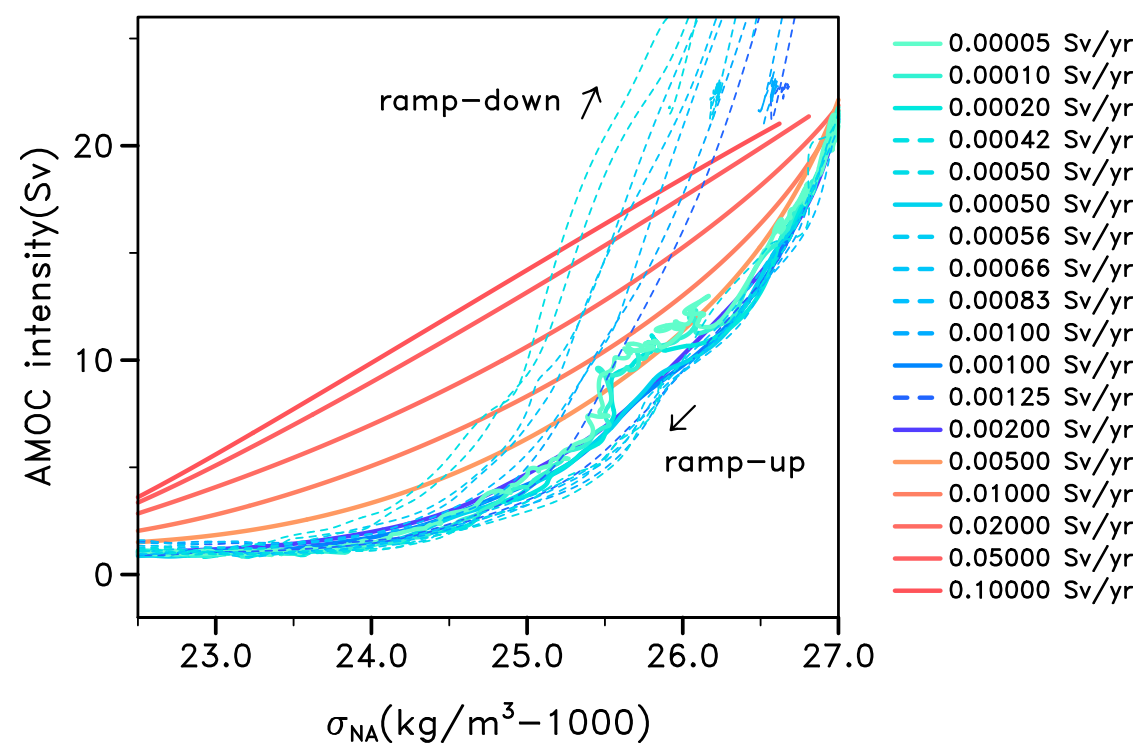

FIG. 5. North Atlantic $\left(90^{\circ} \mathrm{W}-0^{\circ}, 50^{\circ}-70^{\circ} \mathrm{N}\right)$ surface density in sigma $\left(\mathrm{kg} \mathrm{m}^{-3}-1000\right)$ vs AMOC intensity (Sv). A 100-yr Lanczos low-pass filter was applied, and the result is not sensitive to the cutoff frequency. Note that during the ramp-up period the surface density control on the AMOC intensity is almost rate independent for the static-dominant experiments (bluish) whereas it is rate dependent for the dynamic-dominant experiments (reddish).

\section{2) Modulations}

\section{(i) Horizontal redistribution of the forcing}

Under especially slowly increasing FWF forcing, more leakage of freshwater into other ocean basins would be expected. Such a forcing redistribution effect is illustrated in Fig. 7 as surface density distributions when the TIFWF is

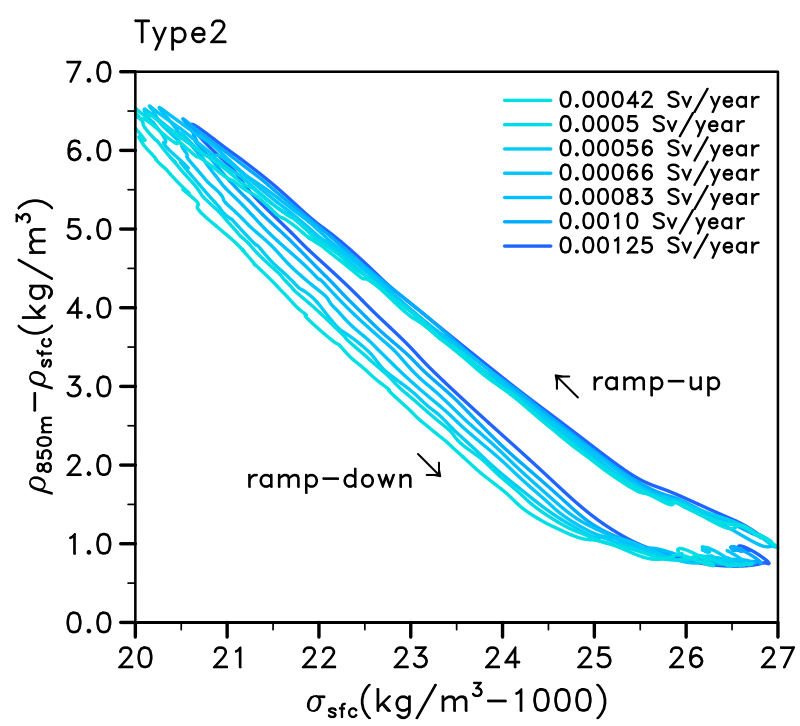

FIG. 6. Relationship between North Atlantic $\left(50^{\circ}-70^{\circ} \mathrm{N}\right)$ surface density $\left(\mathrm{kg} \mathrm{m}^{-3}-1000\right)$ and stratification $\left(\mathrm{kg} \mathrm{m}^{-3}\right)$ during the full hysteresis loop obtained from the type- 2 experiments. The stratification is measured by the density gradient between $850 \mathrm{~m}$ and the surface. equivalent to the global sea level rise of $10 \mathrm{~m}$ (at time $t^{*}$ in Fig. 1 and Table 1). Note that in Fig. 7, surface density is shown as anomalies against a reference density, which is an area average in North Atlantic (Table 1), to more easily compare with the forcing area density. Under rapidly increasing forcing (upper left), the North Pacific and the Southern Ocean have much higher surface density than the North Atlantic because freshwater anomalies have not had enough time to escape the forcing area. Under slowly varying forcing (lower right), regions outside the forcing area are much fresher than fastvarying cases since the freshwater anomalies have escaped the North Atlantic and only a portion has remained. Thus, when the same amount of freshwater is given, the North Atlantic density can remain relatively high under slowly varying forcing, and more TIFWF is required to achieve the AMOC collapse. Namely, the efficiency of the given FWF to induce an AMOC bifurcation is reduced as the forcing time scale increases.

Here, for a quantitative comparison of the efficiency depending on the forcing rate, we computed effective TIFWF for the type-1 experiments at time $t^{*}$ (Table 1). Effective TIFWF, which is estimated based on the salinity change in the Atlantic basin (see the appendix), represents the freshwater amount required for the given salinity reduction. The term "effective" is used in the following sense; if, for example, $2 \mathrm{~m}$ (in eSLE) of $10 \mathrm{~m}$ of the given freshwater amount has been exported outside the Atlantic, only the remaining $8 \mathrm{~m}$ can have the "effect" on the salinity reduction. The results for each experiment are shown in Fig. 8a, normalized to the most fast-varying forcing case. As expected, the effective TIFWF tends to increase with the rate, showing that under slowly increasing forcing, a large amount of the externally forced freshwater is exported to the outside of the basin. The relationship 


\section{Surface density distribution}
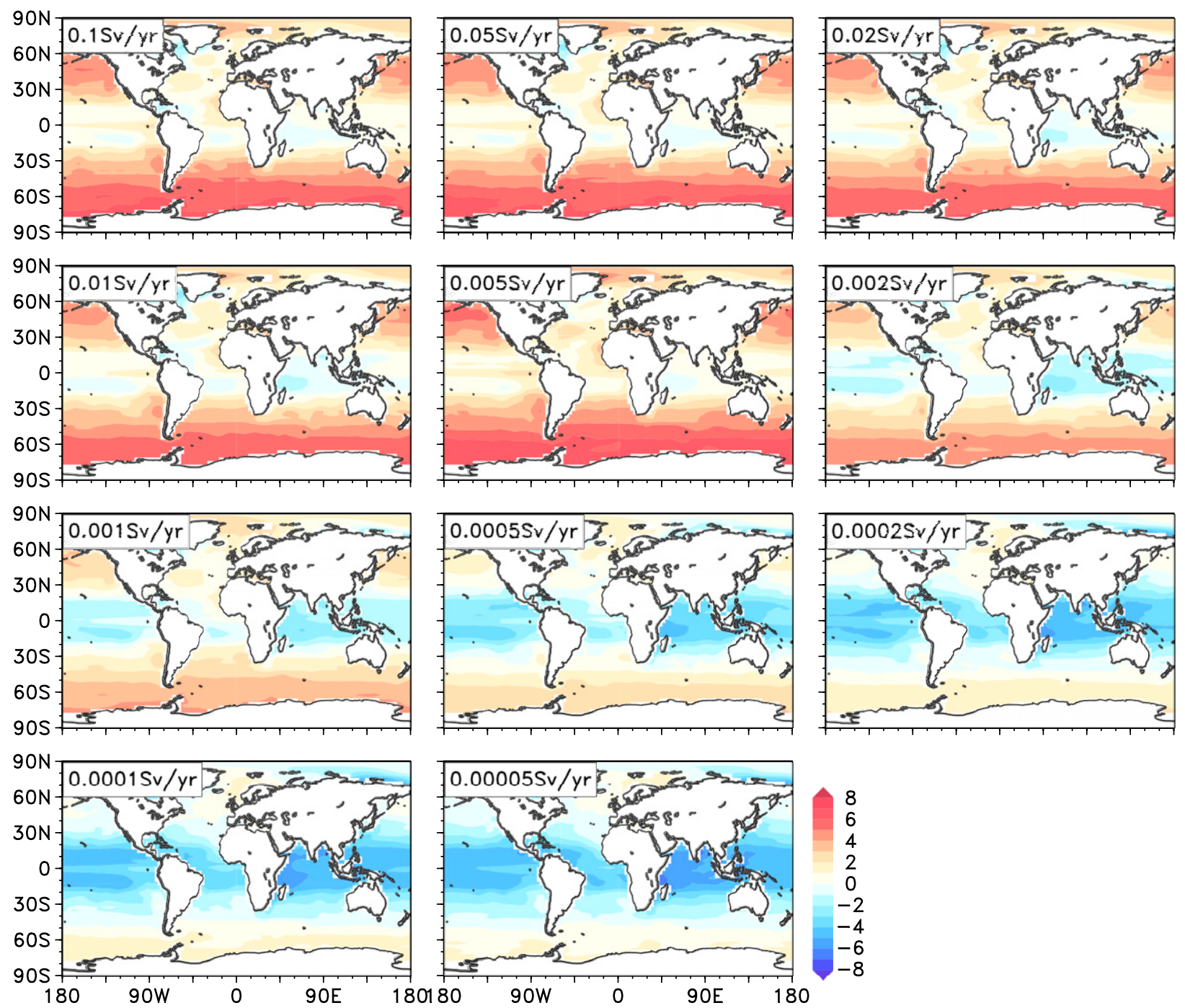

FIG. 7. Annual-mean surface density anomalies $\left(\mathrm{kg} \mathrm{m}^{-3}\right)$ with respect to the North Atlantic $\left(50^{\circ}-70^{\circ} \mathrm{N}\right)$ area average when the TIFWF is $10 \mathrm{~m}$ in the eSLE. The North Atlantic area averages are given in Table 1.

is not linear, however, with saturation occurring near the boundary between static- and dynamic-dominant regimes (about $0.002 \mathrm{~Sv} \mathrm{yr}^{-1}$ ).

We further compute $\int_{0}^{t^{*}}\left(\tilde{W}_{\mathrm{THC}}+\tilde{W}_{\mathrm{az}}\right)^{\prime} d t$ from Eq. (5), where the prime denotes the deviation from the unperturbed state, to measure the imported/exported freshwater volume by circulation. Here, an assumption was made that the equilibrated transport does not change over time such that deviations $\left(\tilde{W}_{\mathrm{THC}}^{\prime}\right.$ and $\left.\tilde{W}_{\mathrm{az}}^{\prime}\right)$ are always calculated against the unperturbed state. The balanced flux against which the deviations are calculated can also change with time through adjustment, but this effect is not considered by the assumption.

Figure $8 \mathrm{~b}$ shows that the anomalous freshwater export by a combination of overturning and azonal circulations decreases with the forcing rate. The terms $\tilde{W}_{\mathrm{THC}}^{\prime}$ and $\tilde{W}_{\mathrm{az}}^{\prime}$ are large negative and positive under the slowly increasing forcing experiment, respectively, and they gradually decrease as the forcing changes faster. Namely, of the given freshwater of $10 \mathrm{~m}$, approximately $4 \mathrm{~m}$ is exported under the most slowly varying forcing, whereas it is only a half of that under fast-varying forcing. Among the two components, it is the overturning circulation (green crosses) that is primarily responsible for freshwater removal, and transport by the azonal circulation (yellow crosses) changes its sign depending on the rate.

In LOVECLIM, the AMOC imports freshwater into the Atlantic $\left(\tilde{W}_{\text {THC }}>0\right)$ at the unperturbed state. Positive $\tilde{W}_{\text {THC }}$ means negative feedback; as the AMOC is weakened by the FWF [decrease in the magnitude of $v$ in Eq. (4a)]. freshwater import by the AMOC also weakens such that the Atlantic basin becomes saltier. Namely, AMOC weakening produces anomalous 
TABLE 1. Time to reach $10 \mathrm{~m}$ of TIFWF $\left(t^{*}\right)$ and North Atlantic $\left(50^{\circ}-70^{\circ} \mathrm{N}\right)$ surface density at $t^{*}$.

\begin{tabular}{lcc}
\hline \hline Forcing rate $\left(\mathrm{Sv} \mathrm{yr}^{-1}\right)$ & $t^{*}(\mathrm{yr})$ & $\rho_{\text {sfc }}\left(t^{*}\right)\left(\mathrm{kg} \mathrm{m}^{-3}\right)$ \\
\hline 0.00005 & 2150 & 1026.36 \\
0.0001 & 1520 & 1026.12 \\
0.0002 & 1074 & 1025.62 \\
0.0005 & 679 & 1024.80 \\
0.001 & 480 & 1023.42 \\
0.002 & 339 & 1022.91 \\
0.005 & 214 & 1021.05 \\
0.01 & 164 & 1021.75 \\
0.02 & 139 & 1021.59 \\
0.05 & 124 & 1021.31 \\
0.1 & 119 & 1021.33 \\
\hline
\end{tabular}

freshwater export, so the largest export is expected in the experiment showing the weakest AMOC. However, in Figs. $8 \mathrm{~b}$ and 8c, the largest export is found in the strongest AMOC case (the $0.00005 \mathrm{~Sv} \mathrm{yr}^{-1}$ experiment). These results seem counterintuitive, but they can be understandable with caution because Fig. $8 \mathrm{~b}$ reflects the integrated effect over time. The integrated freshwater removal is larger in slowly varying forcing because the feedback operates over a longer time. In other words, the magnitude itself $\left(\tilde{W}_{\mathrm{THC}}^{\prime}\right)$ is small, but its cumulative effect $\left(\int_{0}^{t *} \tilde{W}_{\mathrm{THC}}^{\prime} d t\right)$ is large due to large $t^{*}$.

Note that $\tilde{W}_{\text {THC }}>0$ contrasts with the observation in which $\tilde{W}_{\text {THC }}$ is estimated to be negative (Weijer et al. 2019; Hofmann and Rahmstorf 2009; Garzoli et al. 2013). Positive $\tilde{W}_{\text {THC }}$ has been reported to be a common bias in current coupled climate models due presumably to the fresh bias in the South Atlantic (de Vries and Weber 2005; Mecking et al. 2017; Weijer et al. 2019). Since the sign of $\tilde{W}_{\text {THC }}$ determines the sign of feedback, it is often used as a stability indicator (positive for monostability and negative for bistability), with the positive bias being counted as the cause of failure of climate models to simulate bistable AMOC. Although a bias correction may lead to a different conclusion through an opposite direction of feedback, we do not apply it in this study where the AMOC hysteresis is successfully simulated without it.

Overall, the forcing redistribution plays a role in widening the hysteresis because only a portion of the given forcing can be used to reduce the Atlantic density, and more freshwater input is required for the AMOC collapse. This widening effect is more prominent in the slowly varying forcing since the additionally required freshwater input is larger (due to the low efficiency) than in the fast-varying forcing. In contrast, the hysteresis of the fast-varying forcing is least affected by its high efficiency. Therefore, different efficiencies to redistribute the forcing for different forcing rates result in a convergence of hysteresis, narrowing the gap between the experiments.

\section{(ii) Atmospheric feedback}

Here, we investigate atmospheric feedback. In all experiments, the net precipitation (precipitation minus evaporation) in the North Atlantic increases as the AMOC is weakened, which is due to a larger decrease in evaporation than in precipitation. The suppressed evaporation is attributed to surface cooling of the North Atlantic Ocean, induced by reduced meridional heat transport (not shown). Therefore, this hydrological response acts as positive feedback by adding more freshwater influx. This promotes bifurcation and narrows the hysteresis width for all experiments.

Now, we need to identify how this modulates the hysteresis "rate dependency." To this end, we measured the freshwater volume supplemented by hydrological change $\left(F_{\text {sfc }}\right)$ for each experiment as

$$
F_{\mathrm{sfc}}=\int_{0}^{t^{*}}(P-E)^{\prime} d t,
$$

where $P$ and $E\left(\mathrm{~m}^{3} \mathrm{~s}^{-1}\right)$ are obtained by multiplying the Atlantic $\left(33^{\circ} \mathrm{S}-70^{\circ} \mathrm{N}\right)$ surface area by the area-averaged surface flux $\left(\mathrm{m} \mathrm{s}^{-1}\right)$ over the basin. Again, it was assumed that the balanced flux is fixed to that of the unperturbed state. In Fig. $8 \mathrm{~d}, F_{\text {sfc }}$, converted into the eSLE, is displayed. A tendency was observed in which $F_{\text {sfc }}$ decreases with the forcing rate, although some nonlinearities were found in the slow and fast extremes of FWF forcing. This indicates that the bifurcation is more accelerated and that the hysteresis is more narrowed under slowly varying forcing. Thus, the rate-dependent hydrology response induces divergence in hysteresis diagrams.

\section{Discussion}

The AMOC bifurcation under time-varying forcing and the associated mechanisms have been examined using an Earth system model. A delayed AMOC collapse was observed under rapidly increasing forcing, indicating that it occurred at a higher FWF value than expected in the equilibrium response. SS1997 and A2019 also investigated the forcing ratedependent bifurcation of the AMOC. They concluded that AMOC collapse can occur even before the static bifurcation point if the forcing is increased rapidly - that is, the bifurcation can be advanced by fast increasing forcing. Different conclusions were derived between previous studies and ours because the experimental designs and objectives were different. In the studies of SS1997 and A2019, the forcing scenario took a similar form to type 1 in Fig. 1 (although the forcing was eventually turned off in A2019). However, the level of constant forcing was set to be near the static bifurcation point, and they focused on the stability of the AMOC during the constant forcing period (i.e., after adjustment). In their experiments, the AMOC response during the constant forcing period splits depending on how fast the forcing has been increased; the AMOC recovers from the weakening if the forcing has increased slowly, while it turns into a collapsed state if it has increased rapidly. The AMOC in our study, on the other hand, was shut down for all forcing rates before the FWF was fixed to its maximum value, which is far beyond the static bifurcation point. The unequilibrated AMOC response analyzed in this study, even though a highly idealized scenario was used, may be a more realistic case considering that the meltwater release from the ice sheets is likely to be more pulse-like rather than held constant (Fairbanks 1989; Aharon 2003; Wickert et al. 2013; Vetter et al. 2017). Although the interpretation of 
(a) Normalized effective TIFWF

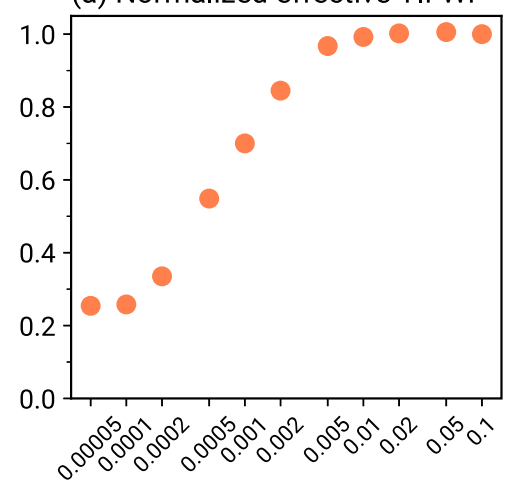

(c) AMOC intensity

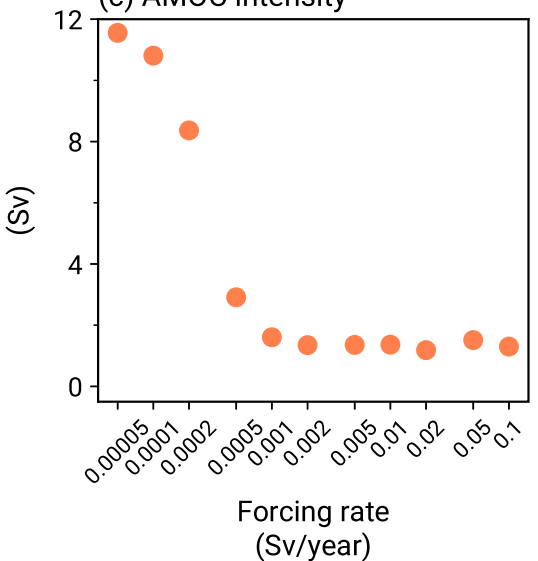

(b) eSLE by transport

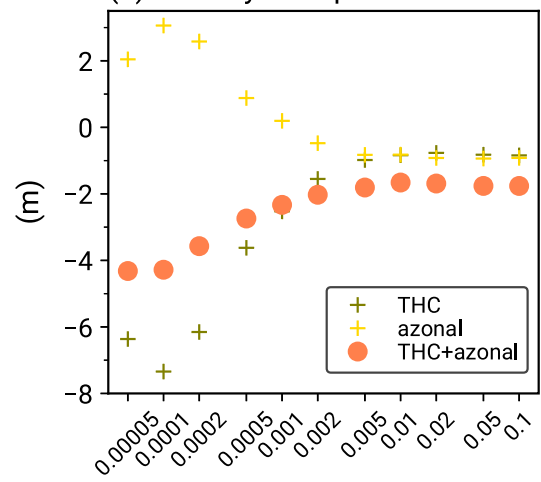

(d) eSLE by P-E

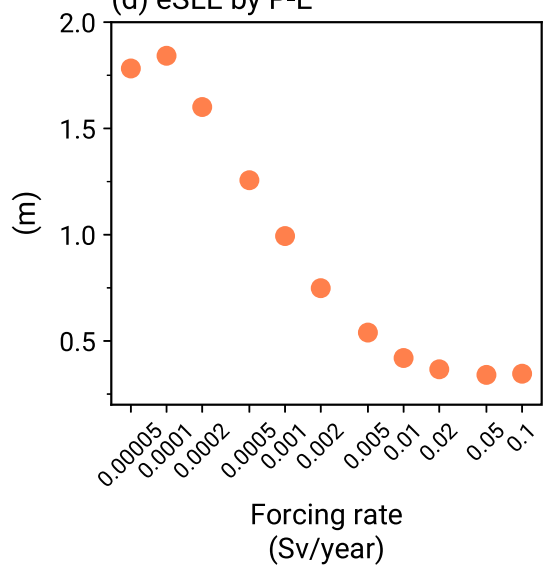

FIG. 8. Scatterplots of each variable vs forcing rate when the TIFWF is $10 \mathrm{~m}$. (a) Forcing efficiency measured as a relative amount of the effective freshwater in the Atlantic basin $\left(33^{\circ} \mathrm{S}-70^{\circ} \mathrm{N}\right)$ in comparison with the $0.1 \mathrm{~Sv} \mathrm{yr}^{-1}$ experiment; (b) oceanic circulation feedback measured as eSLE (m); (c) AMOC intensity (Sv); (d) hydrology feedback measured as $\operatorname{eSLE}(\mathrm{m})$.

whether the fast-varying forcing provokes or delays the bifurcation depends on whether the system has adjusted or not, the simulated results are fundamentally consistent; the bifurcation is preferred when the time-integrated forcing is large. For example, in the study of A2019, tipping by rapid forcing is preferred only if the forcing is turned off sufficiently slowly or if the duration of the forcing is sufficiently long (Fig. 15 in their paper).

As a physical mechanism of the rate-dependent AMOC response, SS1997 proposed the vertical redistribution of the forcing. If the AMOC has not collapsed yet (slowly increased forcing in their study), the AMOC can recover its original strength even if the forcing has not been turned off, since buoyancy anomalies are effectively transferred to depths through convection. In contrast, once bifurcation occurs (rapidly increasing forcing), the forcing can no longer be transferred to the lower layers; thus, strong stratification and a collapsed AMOC state are maintained. This feedback was also simulated by LOVECLIM, as shown in Fig. 6. The stratification change with respect to the surface density change becomes more sensitive after the AMOC collapses as indicated by the larger slopes in the ramp-down period. During the ramp-up period, stratification is strengthened by surface freshening, but it is mitigated by vertical buoyancy transfer by the AMOC. During the ramp-down period, the AMOC was shut down and the surface density increase effectively weakened the stratification in the absence of mitigation. Taken together with the mechanism proposed in section 3, the AMOC provides feedback mainly through horizontal redistribution of forcing until its collapse and thereafter through vertical redistribution.

Although this study presents simulation results under an idealized experimental setting, it reasonably suggests the possibility of new constraints on the past ice sheet melting scenario. For example, Gregoire et al. (2016) explored the effect of the relative timing of two climatic events: the LaurentideCordilleran saddle collapse and Bølling warming. They showed that if the Bølling warming precedes, the saddle collapse is triggered, and the amount of accelerated melting reaches $5 \mathrm{~m}$ in the global mean sea level within 340 years. Conversely, if the Bølling warming does not trigger the separation of the two ice sheets (i.e., the ice sheets are too thick or saddle collapse occurs too early), melting only amounts to $2-5 \mathrm{~m}$, resulting in a lower 


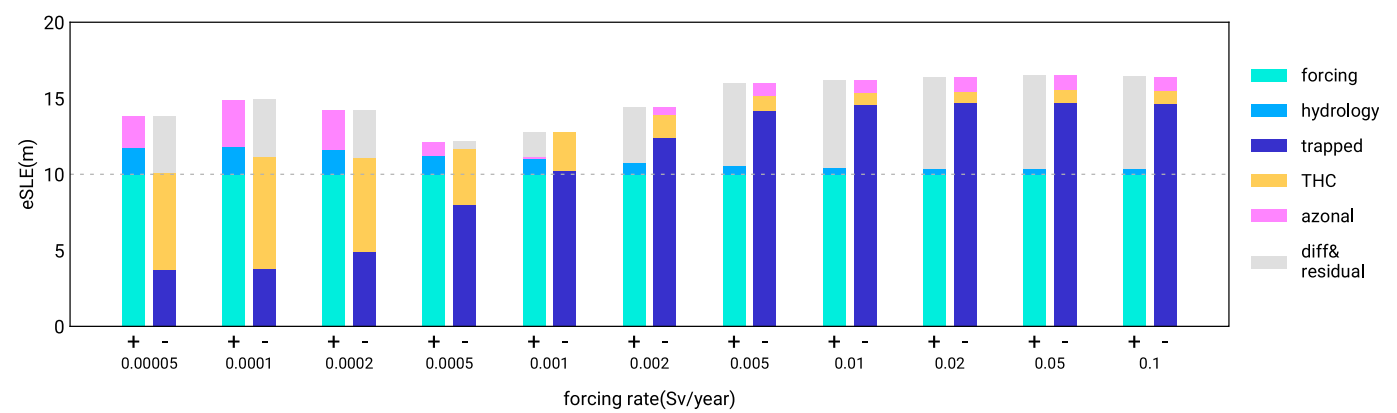

FIG. 9. Bar charts showing contributions from each term of Eq. (5) when the TIFWF is $10 \mathrm{~m}$. Freshwater sources and sinks are marked by a plus sign and minus sign, respectively. Effective TIFWF is marked as "trapped" (navy) as it is used to lower the salinity in the basin. For comparison, all terms were converted into eSLE (m).

rate of release. Considering that the AMOC response to FWF depends on the forcing rate, we will be able to place more confidence in the ice sheet melting scenario that agrees with the AMOC response recorded in the proxy data.

\section{Summary}

In Fig. 9, the source and sink terms of the freshwater budget at TIFWF of $10 \mathrm{~m}$ are summarized for each experiment. Overall, the given freshwater amount in total (colored bars in the plus-sign columns) tends to increase as the forcing rate decreases because of the hydrology (sky blue) and azonal circulation (pink) effects. Despite the large input of freshwater under slowly increased forcing, the freshwater amount removed by overturning circulation (yellow) is also large, leaving a small portion of the given freshwater in the Atlantic basin (navy). The key findings associated with the physical processes for this rate dependency are summarized as follows:

1) The forcing accumulation in the sinking region plays an important role in determining the bifurcation point, but the exact timing of bifurcation is modulated through feedback processes by changes in the hydrology and oceanic circulations.

2) As the forcing increases slowly, more freshwater is required for bifurcation due to strong horizontal redistribution of the forcing, which is driven mainly by overturning circulation.

3) As the forcing increases slowly, anomalous precipitation, which is driven by the decreased evaporation over the cold North Atlantic surface, more effectively provides additional FWF. However, this effect is overwhelmed by finding 2 .

From the viewpoint of hysteresis diagrams (Fig. 2), finding 2 contributes to their convergence because it widens hysteresis for slowly varying forcing more than that for fast-varying forcing, and finding 3 contributes to divergence because it narrows the width for slowly varying forcing more than that for fast-varying forcing.

These findings can be useful from a paleoclimatic perspective because the AMOC change recorded in the proxies may provide a new constraint for ice sheet melting scenarios. In addition, under the current warming by greenhouse gas forcing, which is at an unprecedented rate, many studies have already proposed observational/theoretical evidence that the AMOC weakens as a result of anthropogenic warming (Bakker et al. 2016; Böning et al. 2016; Liu et al. 2017; Rahmstorf et al. 2005). Thus, investigating climate responses to time-varying forcing is required. However, so far, only the AMOC collapserelated mechanisms have been discussed; thus, the mechanism of the off-to-on transitions of the paleo-AMOC or reversibility of the future AMOC requires further investigation. Considering the forcing accumulation effect, type 2-like experiments may be inappropriate for discriminating the inherent physical processes of the on-to-off and off-to-on transitions. Experiments with the same initial condition of a stable AMOC-off state may be useful for this purpose and will be conducted in a future study.

Acknowledgments This research was supported by the Basic Science Research Program through the National Research Foundation of Korea (NRF-2017K1A3A7A03087790, NRF2018R1A5A1024958). Author H.-J. Kim is grateful for financial support from the Hyundai Motor Chung Mong Koo Foundation. The authors also thank the editor and anonymous reviewers for providing insightful suggestions.

Data availability statement.. LOVECLIM is available online (https://www.elic.ucl.ac.be/modx/index.php?id=289).

\section{APPENDIX}

\section{Calculation of Effective TIFWF}

The mean salinity in the Atlantic basin $(\hat{S})$ is

$$
\hat{S} d e f=\frac{1}{V} \int_{V} S d V,
$$

where $V$ represents the total volume of the Atlantic basin. Through subsequent calculations, we aim to measure the amount of freshwater that caused a given salinity change, so we do not take into account how the freshwater was supplied-that is, we do not consider advective/diffusive processes in Eq. (A2). Instead, we measure the freshwater amount as surface flux. First, the evolution of $\hat{S}$ by the surface salinity flux $\left(F_{S}\right)$ can be written as 


$$
\frac{d \hat{S}}{d t}=\frac{1}{V} \int_{V} F_{S} d V
$$

In the model, freshwater flux $\left(q ; \mathrm{m} \mathrm{s}^{-1}\right)$ at the surface is converted into virtual salinity flux $F_{S}$ such that

$$
F_{S}=- \text { Sq. }
$$

Note that $q$ in Eq. (A3) represents the freshwater flux per unit area, so $\mathrm{FWF}(t)\left(\mathrm{m}^{3} \mathrm{~s}^{-1}\right.$; Fig. 1) corresponds to the multiplication of the Atlantic surface area and $q$. Plugging Eq. (A3) into Eq. (A2) yields

$$
\begin{gathered}
\frac{d \hat{S}}{d t}=-\frac{1}{V} \int_{V} \mathrm{Sq} d V \approx-\frac{\hat{S}}{V} \mathrm{FWF} \text { and } \\
\frac{1}{\hat{S}} \frac{d \hat{S}}{d t}=\frac{d}{d t} \ln \hat{S}=-\frac{1}{V} \mathrm{FWF} .
\end{gathered}
$$

Integrating Eq. (A5) over time gives

$$
\ln \hat{S}_{1}-\ln \hat{S}_{0}=-\frac{1}{V} \int_{0}^{t} \mathrm{FWF} d t=-\frac{V_{\mathrm{FW}}}{V},
$$

where subscripts 0 and 1 represent the initial and final states, respectively, and $V_{\mathrm{FW}}$ is the freshwater amount $\left(\mathrm{m}^{3}\right)$. Rewriting Eq. (A6) to yield an equation for $V_{\mathrm{FW}}$ gives

$$
V_{\mathrm{FW}}=V \ln \left(\hat{S}_{0} / \hat{S}_{1}\right) .
$$

\section{REFERENCES}

Aharon, P., 2003: Meltwater flooding events in the Gulf of Mexico revisited: Implications for rapid climate changes during the last deglaciation. Paleoceanography, 18, 1079, https://doi.org/ 10.1029/2002PA000840.

Alkhayuon, H., P. Ashwin, L. C. Jackson, C. Quinn, and R. A. Wood, 2019: Basin bifurcations, oscillatory instability and rate-induced thresholds for Atlantic meridional overturning circulation in a global oceanic box model. Proc. Roy. Soc., 475A, https://doi.org/10.1098/rspa.2019.0051.

An, S.-I., H.-J. Kim, and S.-K. Kim, 2021: Rate-dependent hysteresis of the Atlantic meridional overturning circulation system and its asymmetric loop. Geophys. Res. Lett., 48, e2020GL090132, https://doi.org/10.1029/2020GL090132.

Baer, S. M., and E. M. Gaekel, 2008: Slow acceleration and deacceleration through a Hopf bifurcation: Power ramps, target nucleation, and elliptic bursting. Phys. Rev., 78E, 036205, https://doi.org/10.1103/PhysRevE.78.036205.

Bakker, P., and Coauthors, 2016: Fate of the Atlantic meridional overturning circulation: Strong decline under continued warming and Greenland melting. Geophys. Res. Lett., 43, 12 252-12 260, https://doi.org/10.1002/2016GL070457.

Bergeot, B., A. Almeida, B. Gazengel, C. Vergez, and D. Ferrand, 2014: Response of an artificially blown clarinet to different blowing pressure profiles. J. Acoust. Soc. Amer., 135, 479-490, https://doi.org/10.1121/1.4835755.

Bitz, C. M., J. C. H. Chiang, W. Cheng, and J. J. Barsugli, 2007: Rates of thermohaline recovery from freshwater pulses in modern, Last Glacial Maximum, and greenhouse warming climates. Geophys. Res. Lett., 34, L07708, https://doi.org/10.1029/2006GL029237.
Bonciolini, G., D. Ebi, E. Boujo, and N. Noiray, 2018: Experiments and modelling of rate-dependent transition delay in a stochastic subcritical bifurcation. Roy. Soc. Open Sci., 5, 172078, https://doi.org/10.1098/rsos.172078.

Böning, C. W., E. Behrens, A. Biastoch, K. Getzlaff, and J. L. Bamber, 2016: Emerging impact of Greenland meltwater on deepwater formation in the North Atlantic Ocean. Nat. Geosci., 9, 523-527, https://doi.org/10.1038/ ngeo2740.

Broecker, W. S., D. M. Peteet, and D. Rind, 1985: Does the oceanatmosphere system have more than one stable mode of operation? Nature, 315, 21-26, https://doi.org/10.1038/315021a0.

Brovkin, V., A. Ganapolski, and Y. Svirezhev, 1997: A continuous climate-vegetation classification for use in climate-biosphere studies. Ecol. Modell., 101, 251-261, https://doi.org/10.1016/ S0304-3800(97)00049-5.

Clark, P. U., S. J. Marshall, G. K. C. Clarke, S. W. Hostetler, J. M. Licciardi, and J. T. Teller, 2001: Freshwater forcing of abrupt climate change during the last glaciation freshwater forcing of abrupt climate change during the last glaciation. Science, 293, 283-287, https://doi.org/10.1126/science.1062517.

_, N. G. Pisias, T. F. Stocker, and A. J. Weaver, 2002: The role of the thermohaline circulation in abrupt climate change. Nature, 415, 863-869, https://doi.org/10.1038/415863a.

Delworth, T. L., and Coauthors, 2008: The potential for abrupt change in the Atlantic meridional overturning circulation. Abrupt climate change: A report by the U.S. Climate Change Science Program and the Subcommittee on Global Change Research, U.S. Geological Survey, 258-359.

de Vries, P., and S. L. Weber, 2005: The Atlantic freshwater budget as a diagnostic for the existence of a stable shut down of the meridional overturning circulation. Geophys. Res. Lett., 32, L09606, https://doi.org/10.1029/2004GL021450.

Fairbanks, G. R., 1989: A 17,000-year glacio-eustatic sea level record; influence of glacial melting rates on the Younger Dryas event and deep-ocean circulation. Nature, 342, 637-642, https://doi.org/10.1038/342637a0.

Flower, B. P., C. Williams, H. W. Hill, and D. W. Hastings, 2011: Laurentide ice sheet meltwater and the Atlantic meridional overturning circulation during the last glacial cycle: A view from the Gulf of Mexico. Abrupt Climate Change: Mechanisms, Patterns, and Impacts, Geophys. Monogr., Vol. 193, Amer. Geophys. Union, 39-56, https://doi.org/10.1029/ 2010 GM001016.

Garzoli, S. L., M. O. Baringer, S. Dong, R. C. Perez, and Q. Yao, 2013: South Atlantic meridional fluxes. Deep-Sea Res. I, 71, 21-32, https://doi.org/10.1016/j.dsr.2012.09.003.

Goosse, H., and T. Fichefet, 1999: Importance of ice-ocean interactions for the global ocean circulation: A model study. J. Geophys. Res., 104, 23 337-23 355, https://doi.org/10.1029/ 1999JC900215.

— - and Coauthors, 2010: Description of the Earth system model of intermediate complexity LOVECLIM version 1.2. Geosci. Model Dev., 3, 603-633, https://doi.org/10.5194/gmd-3-6032010.

Gregoire, L. J., B. Otto-Bliesner, P. J. Valdes, and R. Ivanovic, 2016: Abrupt Bølling warming and ice saddle collapse contributions to the Meltwater Pulse 1a rapid sea-level rise. Geophys. Res. Lett., 43, 9130-9137, https://doi.org/10.1002/ 2016 GL070356.

Hawkins, E., R. S. Smith, L. C. Allison, J. M. Gregory, T. J. Woollings, H. Pohlmann, and B. de Cuevas, 2011: Bistability of the Atlantic overturning circulation in a global climate 
model and links to ocean freshwater transport. Geophys. Res. Lett., 38, L10605, https://doi.org/10.1029/2011GL047208.

Henry, L. G., J. F. McManus, W. B. Curry, N. L. Roberts, A. M. Piotrowski, and L. D. Keigwin, 2016: North Atlantic Ocean circulation and abrupt climate change during the last glaciation. Science, 353, 470-474, https://doi.org/10.1126/science.aaf5529.

Heuzé, C., M. Mohrmann, E. Andersson, and E. Crafoord, 2020: Global decline of deep water formation with increasing atmospheric $\mathrm{CO}_{2}$. EarthArXiv, https://doi.org/10.31223/X56K6D.

Hofmann, M., and S. Rahmstorf, 2009: On the stability of the Atlantic meridional overturning circulation. Proc. Natl. Acad. Sci. USA, 106, 20 584-20 589, https://doi.org/10.1073/pnas.0909146106.

$\mathrm{Hu}, \mathrm{A}$., and Coauthors, 2012: Role of the Bering Strait on the hysteresis of the ocean conveyor belt circulation and glacial climate stability. Proc. Natl. Acad. Sci. USA, 109, 6417-6422, https://doi.org/10.1073/pnas.1116014109.

Hughes, T. P., C. Linares, V. Dakos, I. A. van de Leemput, and E. H. van Nes, 2013: Living dangerously on borrowed time during slow, unrecognized regime shifts. Trends Ecol. Evol., 28, 149-155, https://doi.org/10.1016/j.tree.2012.08.022.

Jackson, L. C., and R. A. Wood, 2018: Hysteresis and resilience of the AMOC in an eddy-permitting GCM. Geophys. Res. Lett., 45, 8547-8556, https://doi.org/10.1029/2018GL078104.

Keil, P., T. Mauritsen, J. Jungclaus, C. Hedemann, D. Olonscheck, and R. Ghosh, 2020: Multiple drivers of the North Atlantic warming hole. Nat. Climate Change, 10, 667-671, https:// doi.org/10.1038/s41558-020-0819-8.

Kim, H., and S.-I. An, 2013: On the subarctic North Atlantic cooling due to global warming. Theor. Appl. Climatol., 114, 919, https://doi.org/10.1007/s00704-012-0805-9.

Kim, H.-J., and S.-I. An, 2019: Impact of North Atlantic freshwater forcing on the Pacific meridional overturning circulation under glacial and interglacial conditions. J. Climate, 32, 46414659, https://doi.org/10.1175/JCLI-D-19-0065.1.

Liu, W., and Z. Liu, 2013: A diagnostic indicator of the stability of the Atlantic meridional overturning circulation in CCSM3. J. Climate, 26, 1926-1938, https://doi.org/10.1175/JCLI-D-1100681.1.

— S.-P. Xie, Z. Liu, and J. Zhu, 2017: Overlooked possibility of a collapsed Atlantic meridional overturning circulation in warming climate. Sci. Adv., 3, e1601666, https://doi.org/ 10.1126/sciadv.1601666.

Mandel, P., and T. Erneux, 1987: The slow passage through a steady bifurcation: Delay and memory effects. J. Stat. Phys., 48, 1059-1070, https://doi.org/10.1007/BF01009533.

Mannella, R., F. Moss, and P. V. E. McClintock, 1987: Postponed bifurcations of a ring-laser model with a swept parameter and additive colored noise. Phys. Rev. A, 35, 2560-2566, https:// doi.org/10.1103/PhysRevA.35.2560.
McManus, J. F., J.-M. Gherardi, L. D. Keigwin, and S. BrownLeger, 2004: Collapse and rapid resumption of Atlantic meridional circualtion linked to deglacial climate changes. Nature, 428, 834-837, https://doi.org/10.1038/nature02494.

Mecking, J. V., S. S. Drijfhout, L. C. Jackson, and M. B. Andrews, 2017: The effect of model bias on Atlantic freshwater transport and implications for AMOC bi-stability. Tellus, 69A, 1299910, https://doi.org/10.1080/16000870.2017.1299910.

Opsteegh, J. D., R. J. Haarsma, F. M. Selten, and A. Kattenberg, 1998: ECBILT: A dynamic alternative to mixed boundary conditions in ocean models. Tellus, 50A, 348-367, https:// doi.org/10.3402/tellusa.v50i3.14524.

Premraj, D., K. Suresh, T. Banerjee, and K. Thamilmaran, 2016: An experimental study of slow passage through Hopf and pitchfork bifurcations in a parametrically driven nonlinear oscillator. Commun. Nonlinear Sci. Numer. Simul., 37, 212221, https://doi.org/10.1016/j.cnsns.2016.01.012.

Rahmstorf, S., 1995: Bifurcations of the Atlantic thermohaline circulation in response to changes in the hydrological cycle. Nature, 378, 145-149, https://doi.org/10.1038/378145a0.

_ 1996: On the freshwater forcing and transport of the Atlantic thermohaline circulation. Climate Dyn., 12, 799-811, https:// doi.org/10.1007/s003820050144.

_- 2002: Ocean circulation and climate during the past 120,000 years. Nature, 419, 207-214, https://doi.org/ 10.1038/nature01090.

— , and Coauthors, 2005: Thermohaline circulation hysteresis: A model intercomparison. Geophys. Res. Lett., 32, L23605, https://doi.org/10.1029/2005GL023655.

Stocker, T. F., and A. Schmittner, 1997: Influence of $\mathrm{CO}_{2}$ emission rates on the stability of the thermohaline circulation. Nature, 388, 862-865, https://doi.org/10.1038/42224.

Vetter, L., H. J. Spero, S. M. Eggins, C. Williams, and B. P. Flower, 2017: Oxygen isotope geochemistry of Laurentide ice-sheet meltwater across termination I. Quat. Sci. Rev., 178, 102-117, https://doi.org/10.1016/j.quascirev.2017.10.007.

Weijer, W., and Coauthors, 2019: Stability of the Atlantic meridional overturning circulation: A review and synthesis. J. Geophys. Res. Oceans, 124, 5336-5375, https://doi.org/ 10.1029/2019JC015083.

Wickert, A. D., J. X. Mitrovica, C. Williams, and R. S. Anderson, 2013: Gradual demise of a thin southern Laurentide ice sheet recorded by Mississippi drainage. Nature, 502, 668-671, https://doi.org/10.1038/nature12609.

Wood, R. A., J. M. Rodríguez, R. S. Smith, L. C. Jackson, and E. Hawkins, 2019: Observable, low-order dynamical controls on thresholds of the Atlantic meridional overturning circulation. Climate Dyn., 53, 6815-6834, https://doi.org/10.1007/ s00382-019-04956-1. 